\title{
Variation of skeletal muscle ultrasound imaging intensity in horses after treadmill exercise: a proof of concept for glycogen content estimation
}

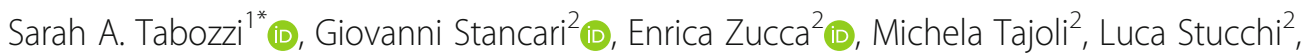 \\ Claudio L. Lafortuna ${ }^{3}$ (D) and Francesco Ferrucci ${ }^{2}$ (D)
}

\begin{abstract}
Background: Glycogen in skeletal muscle is a major source of energy during exercise and an important determinant of endurance capacity, so that its measurement may provide a meaningful marker of athletes' preparation and a possible predictor of performance, both in humans and in equines. Gold standard of glycogen concentration measurement is the histochemical and biochemical analysis of biopsy-derived muscle tissue, an invasive and potentially injuring procedure. Recently, high-frequency ultrasound (US) technology is being exploited in human sports medicine to estimate muscle glycogen content. Therefore, aim of the present study is to evaluate the feasibility of US assessment of muscle glycogen in equines.

Results: US images of gluteus medius (GL) and semitendinosuS (ST) muscles were obtained on eight healthy horses (3-10 years) before and after a steady-state exercise on treadmill (velocity: 4.0-12.5 m/s; duration: 2-20 min; heart rate: 137-218 b/ min). Average image greyscale intensity was significantly different between GL and ST, both before and after exercise $(p<$ 0.001). Comparing baseline and post-exercise US images, significant increase in greyscale intensity has been observed in ST $(p<0.001)$, but not in $\mathrm{GL}(p=0.129)$. The volume of the exercise was significantly correlated with exercise-dependent change in image intensity $\left(R^{2}=0.891\right)$, consistent with a reduction of glycogen muscle stores resulting from aerobic activity.

Conclusions: US technique evidences also in horses muscle changes possibly associated to glycogen utilisation during exercise. Present results on a small sample need to be further confirmed and provide preliminary data warranting future validation by direct glycogen measurement through biopsy technique.
\end{abstract}

Keywords: Ultrasound, Greyscale, Exercise, Treadmill, Muscle glycogen, Horses

\section{Background}

The horse is a versatile and extraordinary athlete, as it can be appreciated in the variety of existing equine sport disciplines. Horses, regardless of their origin and their aptitude, have in common the ability to perform physical

\footnotetext{
* Correspondence: s.tabozzi@gmail.com

'Present Address: Croce Rossa Italiana, Comitato Nazionale, Via Ramazzini 37, Roma, Italy

Full list of author information is available at the end of the article
}

activities, including jumping and running, at a level of performance that surpasses most other similarly sized animals, thanks to their superior specific aerobic capacity [13]. This is due to a number of physiological adaptations, mostly independent of training, including alveolo-capillary features, cardiac size, haemoglobin concentration and musculoskeletal characteristics $[2,5,11$, 13]. Moreover, beside the capabilities of the machinery for the delivery of $\mathrm{O}_{2}$ throughout the entire path from

(c) The Author(s). 2021 Open Access This article is licensed under a Creative Commons Attribution 4.0 International License, which permits use, sharing, adaptation, distribution and reproduction in any medium or format, as long as you give appropriate credit to the original author(s) and the source, provide a link to the Creative Commons licence, and indicate if changes were made. The images or other third party material in this article are included in the article's Creative Commons licence, unless indicated otherwise in a credit line to the material. If material is not included in the article's Creative Commons licence and your intended use is not permitted by statutory regulation or exceeds the permitted use, you will need to obtain permission directly from the copyright holder. To view a copy of this licence, visit http://creativecommons.org/licenses/by/4.0/. The Creative Commons Public Domain Dedication waiver (http://creativecommons.org/publicdomain/zero/1.0/) applies to the data made available in this article, unless otherwise stated in a credit line to the data. 
the alveolar gas to mitochondria, also the availability of energy stores of substrates in skeletal muscle tissue (i.e. glycogen concentration) is recognised to impact on athletic endurance performance. The concentration of glycogen in muscles is reported to be higher in horses, compared to humans and other mammals, being 550$600 \mathrm{mmol} / \mathrm{kg}$ dry weight in equine muscle, as compared with $300-400 \mathrm{mmol} / \mathrm{kg}$ dry weight in human muscle (Snow et al. 1991).

During vigorous exercise, as in the case of most of competitive equine activities, the blood-derived glucose can guarantee less than $10 \%$ of the energy used [14]. The presence of adequate substrate deposits in the muscle cell allows the horse to sustain prolonged exercise. It has been shown that skeletal muscle glycogen depletion is associated with a reduction of exercise capacity and a significant lengthening of recovery times [15]. Since muscle glycogen content is modifiable by adjustments of appropriate dietary regimen in relation with training protocols, the measurement of muscular reserves is a key point in the management of the athlete horse.

At present, the gold-standard measure of muscle glycogen concentration is considered to be achieved by histochemical analysis of percutaneous biopsy samples, generally performed on the gluteus medius. Major limitations of biopsy assessment are the invasiveness and the traumatic action of the procedure: although a single biopsy allows the regeneration of myofibrillar tissue, repeated biopsies with an interval less than 7 weeks or affecting the basement membrane can prevent a complete repair of the muscle and cause proliferation of granulation tissue, with a keloid formation [17]. This represents a major drawback of the measurement of glycogen storage in sport environment, optimally requiring multiple sampling during training and/or pre-post assessment in the occasion of competitions.

Less invasive techniques have been scarcely applied in veterinary medicine. However, clinical studies in human sports medicine validated the use of muscular ultrasound (US) as a possible alternative to muscle glycogen measurement through chemical analysis of biopsy samples $[7,9,18]$.

Based on the osmotic properties of glycogen molecule, binding 3-4g of water for each gram of glycogen [19], the technique has provided the estimate of glycogen availability by assessing the average US intensity on images of human quadriceps, sampled on standardised position, pre and post exercise. High concentration of glycogen (and water) in baseline images is associated to lower average US intensity (darker), while, due to glycogen depletion and the consequent loss water, image intensity shifts towards hyperechoic US intensity (clearer). Results have been confirmed, using biopsies, to quantitatively describe variations in the glycogen content after a relevant depleting exercise [18].
The current study aims to evaluate the use of this technique in equines, in order to explore a non-invasive method, alternative to muscle biopsy, and to provide preliminary background data for future validation studies assessing skeletal muscle glycogen concentration in horses with US technique.

\section{Results}

Figure 1 shows US images relative to ST and GL muscles, acquired before and after exercise in the same anatomical area, as confirmed by the structural landmarks visible in the images. For each muscle, a qualitative difference in US intensity between the two conditions (before and after exercise) can be appreciated, though more evidently for ST muscle.

The quantitative comparison of US images is presented in Fig. 2, which shows the average value of US intensity, in greyscale units, measured in all horses before and after exercise. Student's t-test for paired measurements indicated that both before and after exercise average US intensity is higher in ST muscle than in GL muscle, whereas the same paired test showed that a statistically significant difference between the values observed before and after exercise was found for ST muscle but not for GL muscle.

Figure 3 shows that volume of exercise, as indirectly estimated using the combination of velocity and duration of the tests, is a decreasing function of treadmill velocity, whereas the average cardio-dynamic response observed throughout the steady-state exercise is a linear positive function of velocity.

As shown in Fig. 4, the change of US intensity displayed by ST muscle in individual horses after exercise, expressed as a percent of the pre-exercise value, resulted significantly correlated with the volume of exercise sustained during the test on treadmill with a positive curvilinear trend.

\section{Discussion}

The current study shows that significant changes proportional to treadmill exercise of different intensities and duration, can be detected in US image greyscale intensity of ST muscle in horses and can be interpreted as the decrease of intramuscular glycogen stores, due to their metabolic utilisation during exercise.

Ultrasonography has been introduced in equine medicine in the early 1980s. At present, in the domain of locomotor system, US represents a common veterinary tool for the diagnosis, evaluation and monitoring in the diseases of tendinous, ligamentous and muscular structures [6]. Application of US imaging for muscle glycogen assessment in horses has not been studied before. In humans, the development and validation of US muscle imaging technique for the study of muscle glycogen 


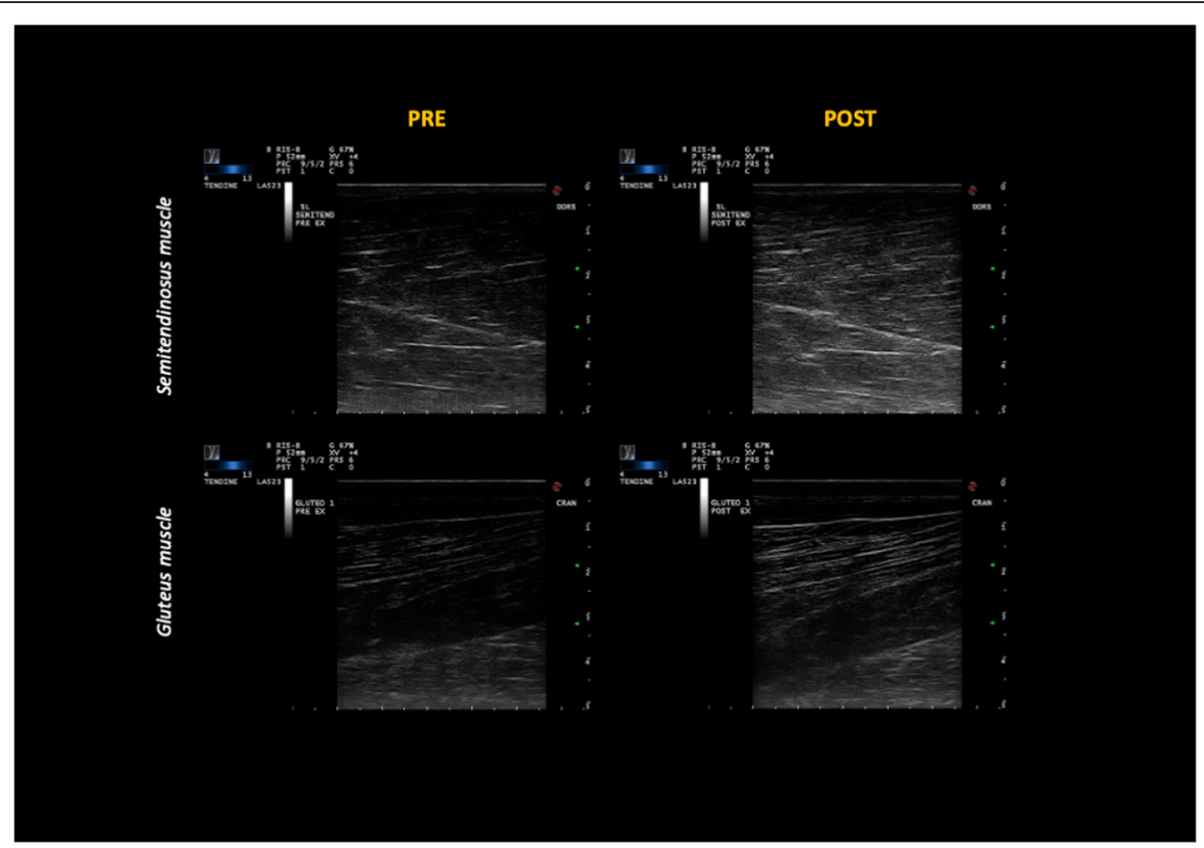

Fig. 1 Qualitative ultrasound images of semitendinosus (ST, upper panels) and gluteus medius (GL, lower panels), acquired before (PRE, left panels) and after (POST, right panels) exercise in the same anatomical area. as confirmed by the structural landmarks visible in the images

contrasted with biopsy sampling has been described for the first time by Hill and Millán (9) and further confirmed by Nieman et al. [18]. Quadriceps muscle US image intensity before the race has been found to be a significant predictor of athletic performance in ultramarathon runners (personal observation, submitted for publication).
Indeed, glycogen stores in muscle provide the principal energy source in prolonged exercise, so that endurance exercise results to induce marked glycogen depletion and to bring human athletes to exhaustion [1]. Also in horses, glycogen depletion is considered a limiting factor to the athletic performance during prolonged physical activity [10].

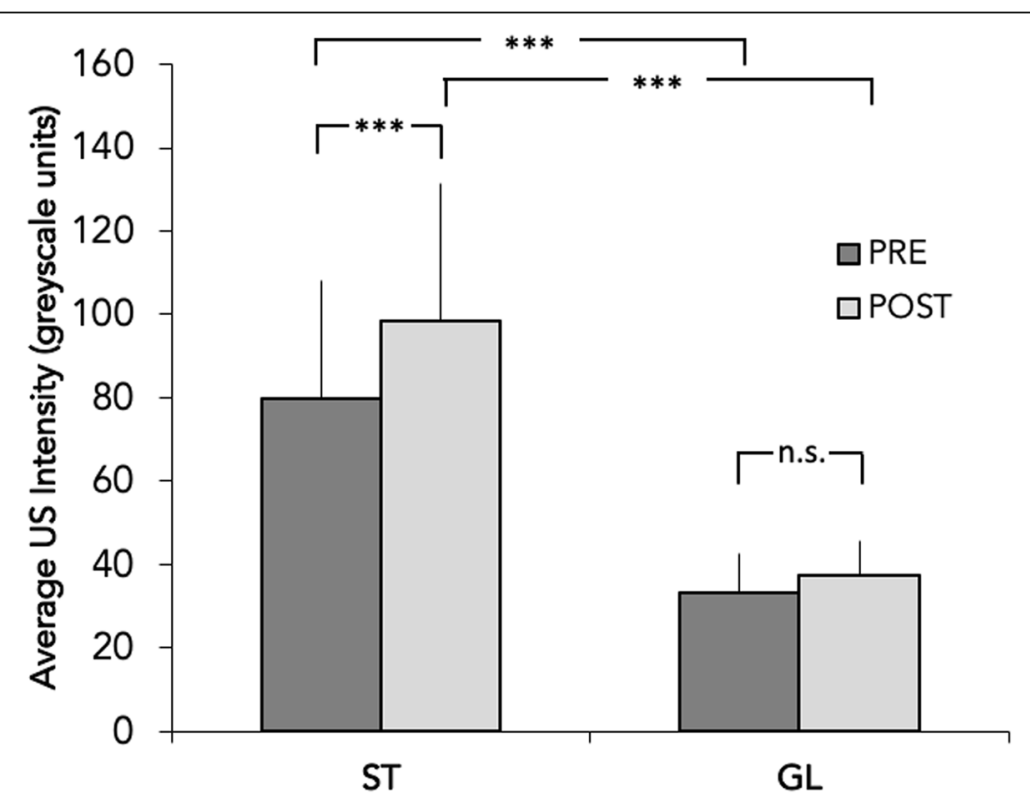

Fig. 2 Average value of ultrasound intensity, in greyscale units, measured in semitendinosus (ST) and gluteus medius (GL) of all horses before (darker bars) and after (lighter bars) exercise. Significance of difference between muscles and between conditions are assessed with a Student's ttest for paired measurements (***: $p<0.001)$ 


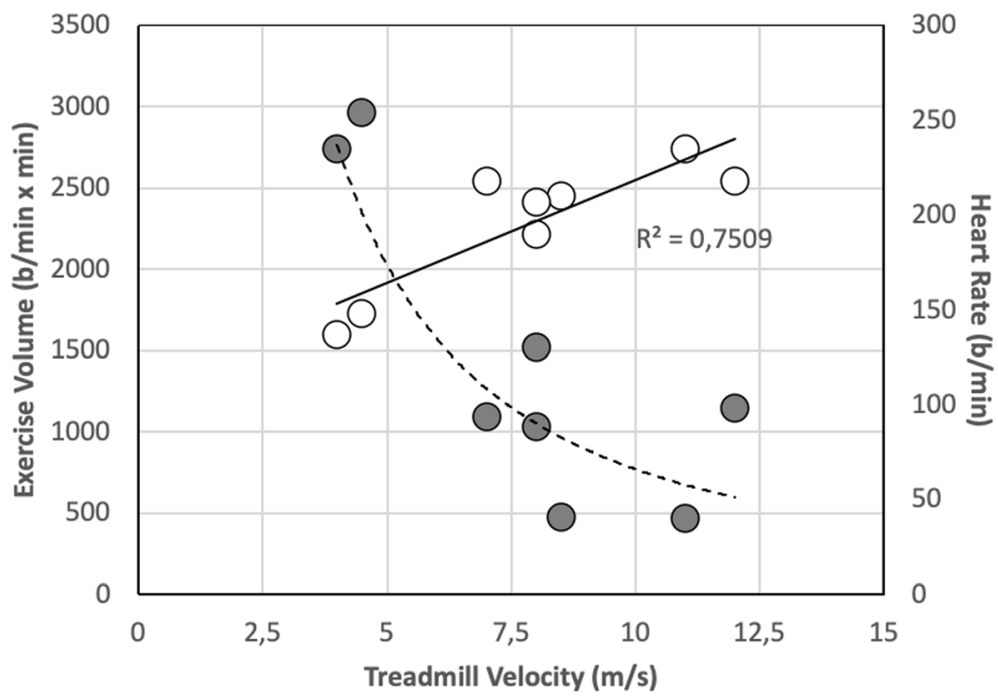

Fig. 3 Volume of exercise performed during the steady-state test (left axis) and attained heart rate (right axis) are plotted as a function of treadmill velocity

Indeed, overall glycogen storage capacity and post exercise levels are reported to vary individually, in horses as well as in humans, depending on training and dietary regimens $[8,20,24]$. Yet, we found in the same individual a significantly different US intensity between GL and ST muscle (see Fig. 2), a finding possibly deriving from a systematic lower glycogen content of ST, due to a different fibre composition among these muscles. In fact, fibre composition of GL and ST was studied in Thoroughbred horses [12] and it was found that Type IIa fibres, which are characterised by the highest glycogen content, account for the $42 \%$ of GL, and $26 \%$ of ST, thus suggesting that a different fibre composition may induce a difference in glycogen content detectable through US imaging.

Although it cannot be excluded that such a different fibre composition in GL and ST might also be due to a different biomechanical role played by these muscles during locomotory activity, Crook et al. [3] could not detect any significant difference in muscle electromyographic

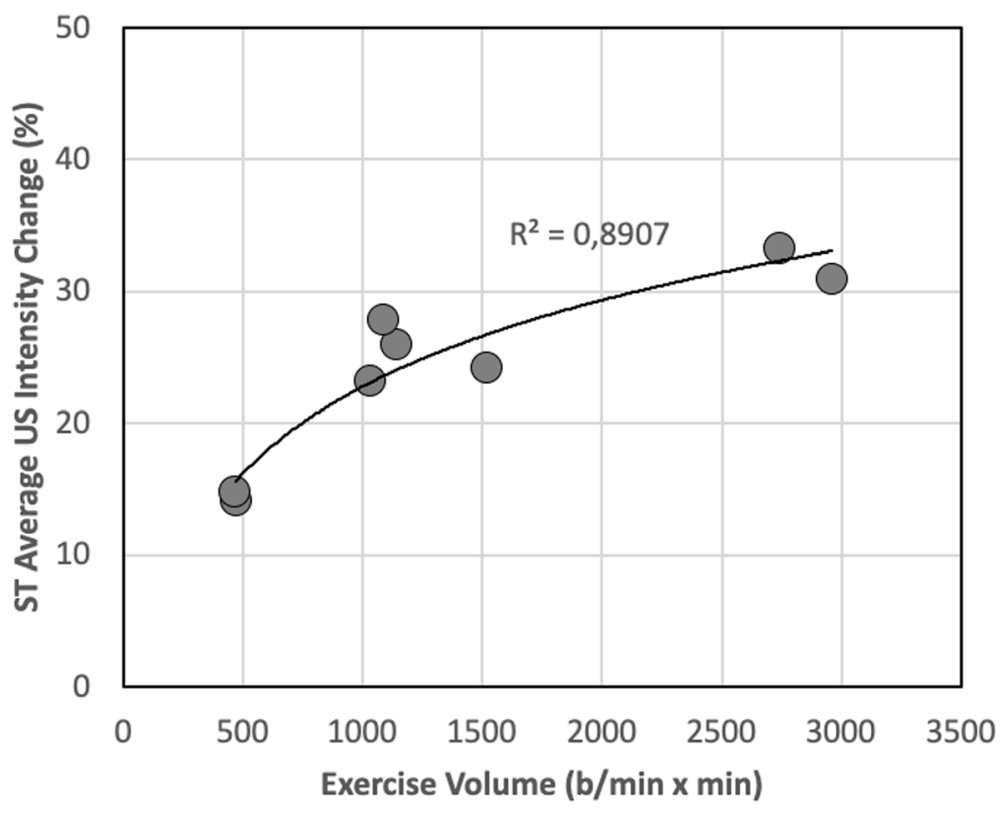

Fig. 4 The change of ultrasound intensity displayed by semitendinosus muscle in individual horses after exercise, expressed as a percent of the pre-exercise value, is plotted as a function of the volume of exercise sustained during the test on treadmill 
activation among hip extensor muscles during equine walk and trot at different velocities and inclines on treadmill. However, it cannot be excluded that part of the overall variability in US intensity measured after exercise in the considered muscles may derive from individual differences in biomechanical (and hence metabolic) muscle involvement deriving from the gait used during the exercise test (trot or canter).

Given the notion that GL muscle has been reported to be fairly more abundant in glycogen rich IIa fibres, it is surprising that we could not detect changes after exercise in its US features associated with glycogen content, at difference with ST muscle (see Fig. 2). Although a linear correlation was reported in human athletes between the specific glycogen content of vastus lateralis muscle (assessed by chemical analysis of specimens obtained through muscle biopsy) and US scores and between their change after exercise exhaustion ([9]; Niemanet al. 2015), a comparison between different muscles is not available. Moreover, horses' muscles are reported to have a considerably higher glycogen content than that of humans [21] and GL in particular may have a glycogen concentration out of the range of the explored linearity in the correlation between muscle glycogen content and US imaging found in humans. With very high glycogen concentrations, the correspondingly more elevated water content in tissues may interfere with US imaging (lower greyscale intensities and darker images) and prevent an accurate and proportional detection of glycogen. This is a serious issue, potentially limiting the use of US in horses and requiring a further detailed clarification.

However, present results show that US grayscale intensity displayed by ST muscle is significantly affected by exercise. Moreover, the muscle US changes after steadystate exercise bouts are indeed proportional to the volume of performed activity (see Figs. 2 and 4), considered as the product of average HR attained throughout the test multiplied by the duration of the test, and may reflect the expected decrease of skeletal muscle glycogen stores induced by the aerobic activity sustained during exercise. Due to the linear correlation between HR and $\mathrm{V}^{\prime} \mathrm{O}_{2}$ observed in horses during locomotion on treadmill [4], the so-calculated volume of exercise directly correlates with the overall amount of $\mathrm{O}_{2}$ utilised during the exercise test and with glucose therein oxidised as energy substrate, neglecting the shift between carbohydrate and fats utilisation at the different intensities of exercise. Thus, the amount of muscle glycogen reduction, as supposedly represented by the changes in US muscle features, seems to closely match the metabolic demand imposed by exercise. So, it appears that, during a single continuous session of aerobic activity, the overall balance of glycogen depletion is dominated by the total volume of exercise more than the absolute intensity of exercise: during sessions of near to maximal exercise, due to the low sustainability, the percentage of total glycogen used is relatively lower, compared to a more protracted exercise of lower intensity, when a substantial depletion of total deposits ensues, albeit at a slower rate $[16,22,23]$.

It is interesting to remark that a certain degree of alinearity in the relation between US intensity change and exercise volume can be appreciated in Fig. 4. Since, in the present exercise protocol, small volumes of exercise correspond to very short and intense exercise bouts, a smaller change in US intensity (and hence glycogen utilisation) during small volumes of exercise may be hypothesised to result from a high contribution of anaerobic energy sources sustaining these intense and short exercise bouts.

\section{Conclusions}

In conclusion, we observed significant changes in US greyscale intensity in ST muscle imaging after exercise, proportional to the energy requirements of the exercise volume. We postulate that these changes qualitatively correspond to the reduction of muscle glycogen stores induced by the energy demand of exercise. Since, also in horses, the use of ultrasound technology may offer a low-cost, non-invasive and simple alternative to histochemical analysis through muscle biopsy for glycogen assessment, these results are promising.

However, due to the limited number of horses and tested muscles and absence of validation against muscle biopsy in equines, some caution should be used in interpreting present results, and further investigation seems warranted in the future to validate the technique also in horses.

\section{Methods}

Gluteus medius muscle (GL) and semitendinosus muscle (ST) have been investigated with US scan in 8 healthy horses, before and after treadmill exercise.

\section{Subjects}

Eight private horses (Thoroughbreds $(N=3)$, Standardbreds $(N=3)$, Hackney ponies $(N=2)$; 3 females, 3 males and 2 geldings; $3-10$ years old; mean body mass: $452 \pm$ $113 \mathrm{~kg}$ ) took part into the experiments. All horses were actively in training as racehorses $(N=5)$, show jumping $(\mathrm{N}=2)$ or combined driving $(N=1)$. The horses had been admitted to the Equine Medicine Unit of the Veterinary University Hospital as outpatients for a performance profiling test. All the horses admitted to the study had no history of rhabdomyolysis syndrome and did not show an increase of muscular enzymes after exercise tests. Before the day of the experiment, horses had been housed in the facilities of the laboratory for 3 days and 
were fed with concentrate $(2-4 \mathrm{~kg} /$ day $)$ and hay ad libitum.

The protocol of the present study was a part of the clinical procedures for the functional evaluation of exercise performance which are in allowance with the institutional ethical standards for veterinary diagnostics. All horses' owners gave a written informed consent.

\section{US image acquisition and analysis}

All image acquisitions were performed while the horse was restrained in crossties in the clinical standing stock and stand squarely with equal weight on all four limbs, on a firm, level ground surface. The appropriate sites for US imaging were chosen using anatomical landmarks. Specifically, for GL, first a line was drawn between the sacral tuber to the tuber coxae. Then, starting from the middle of this line another line was drawn to the ischiatic tuberosity. The site for the ultrasonographic scan was identified at the cranial $1 / 3$ of the latter line. Instead, for ST a line was drawn from the ischiatic tuberosity perpendicular to the ground, and the site was chosen at $1 / 3$ of the distance between the ischiatic tuberosity and the cutaneous area corresponding to the distal portion of ST. Two rectangular shaped shaves, corresponding to transducer surface, were performed on the coat of the horses in the area corresponding to the sites for the ultrasonographic scan of GL and ST muscles. This procedure avoided possible different positioning of the probe before and after exercise.

The acquisitions were performed by a single operator, using default settings of brightness, contrast and image depth for visualization, with a $12 \mathrm{MHz}$ linear transducer and a standard diagnostic high-resolution ultrasound system (ClassC Esaote, Italy). All the settings were maintained during the scan procedures before and after the treadmill exercise.

The transducer was oriented longitudinally to the muscle and ultrasound gel was applied on the probe. During acquisition pressure applied to the probe was minimal, to avoid any undue distortion of tissue under analysis. The same procedure was repeated for acquisition of images within $30 \mathrm{~min}$ after the termination of the exercise test.

Three images for each muscle were acquired in DICOM format, both before and after treadmill exercise, and were analysed using the public domain Java image processing program, named ImageJ. A trained operator manually selected for each image a region of interest, including all the visible part of the analysed muscle, excluding superficial and deep fasciae and calculated average intensity of selected area on a $0-254$ greyscale. Scores obtained on the three images of the same muscle were averaged for each condition. Repeatability of measurement with probe repositioning was previously tested on nine consecutive images of the same muscle and yielded a coefficient of variation of $1.992 \%$.

\section{Exercise test}

All horses exercised on high speed treadmill ( $\mathrm{S}$ to I, SATO, Sweden) on flat. After a 7 -min warm up (4 min pacing at $1.5 \mathrm{~m} / \mathrm{s}$ and $3 \mathrm{~min}$ trotting at $4.0 \mathrm{~m} / \mathrm{s}$ ) horses performed a test in steady-state conditions with a

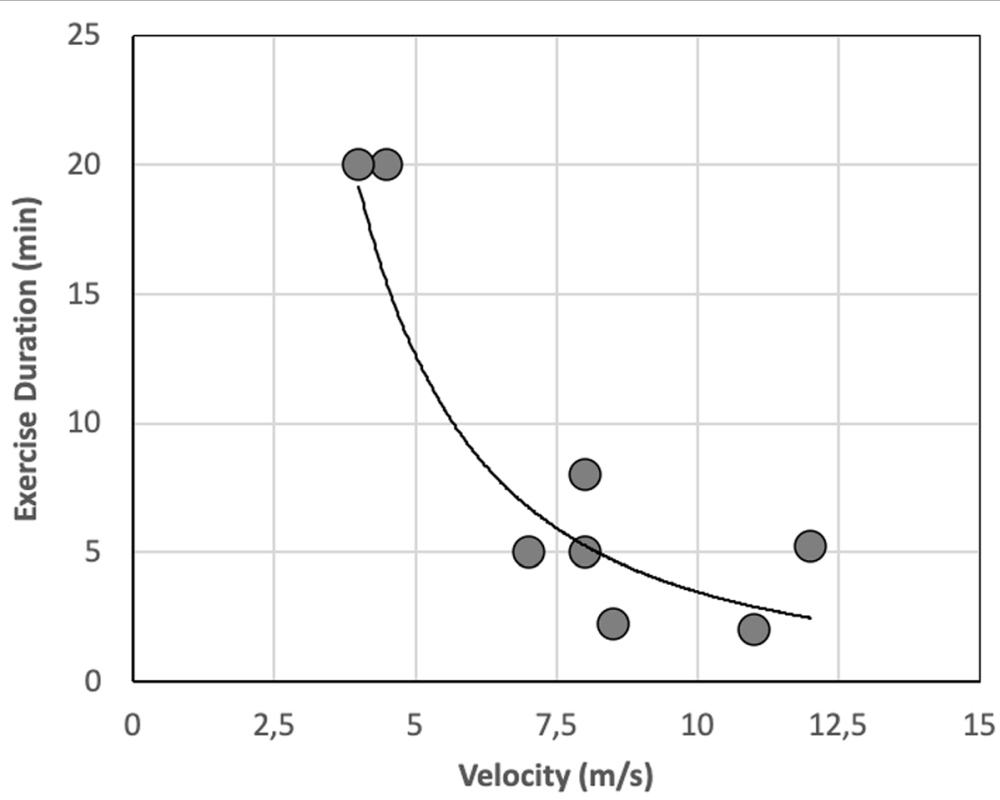

Fig. 5 The relationship between duration of exertion and treadmill velocity performed during the steady-state exercise by the different horses participating to the experiment 
combination of velocity and duration appropriate for the individual level of physical conditioning, in a range of velocities comprised between 4.0 and $12 \mathrm{~m} / \mathrm{s}$, with a duration ranging from 2 to $20 \mathrm{~min}$. The combination of duration of test and treadmill velocity performed during the steady-state exercise by the different horses participating to the experiment is presented in Fig. 5, which shows that duration of exertion is a decreasing function of treadmill velocity. Throughout the entire duration of treadmill exercise, heart rate (HR) was continuously monitored and recorded by means of a wearable meter (Polar Equine heart rate monitor, M400).

Since, during exercise, HR is a linear function of the corresponding oxygen consumption $\left(\mathrm{V}^{\prime} \mathrm{O}_{2}\right)$, the volume of exercise performed during the test was estimated by the product of the average HR during the steady-state period times the duration of this exertion, which represents the total amount of energy substrates utilised in the same period.

\section{Statistical analysis}

All data are presented as mean value \pm SD. Student's Ttest for repeated measurements was used to assess significance of US intensity differences between GL and ST within each condition, and between conditions for each muscle. Regression line equations were calculated using the least square model. $P$ values less than 0.05 were considered statistically significant. All statistical procedures were performed using IBM SPSS Statistics package (v. 25 for MacOs).

\section{Abbreviations}

US: Ultrasound; GL: Gluteus medius muscle; ST: Semitendinosus muscle; HR: Heart rate; $\mathrm{O}_{2}$ : Oxygen; $V^{\prime} \mathrm{O}_{2}$ : Oxygen consumption

\section{Acknowledgements}

We are grateful to the staff and students of the Laboratorio di Medicina Sportiva del Cavallo "Franco Tradati" for their help in management of horses during imaging procedure and exercise on treadmill. We would also like to thank Ms. Bianca Conturba for her technical help throughout the study.

\section{Availability of data and material}

The datasets used and/or analysed during the current study are available from the corresponding author on reasonable request.

\section{Authors' contributions}

S.A.T. participated in conceiving and designing the study, contributed to study execution, data analysis and drafted the manuscript; G.S. participated in designing the study, executed US imaging, contributed to data analysis and preparation of the manuscript; E.Z. contributed to US imaging, data analysis and preparation of the manuscript; M.T. contributed to data analysis and preparation of the manuscript; L.S. contributed to the management of exercise testing and data analysis; C.L.L. conceived and designed the study, contributed to data analysis, edited the manuscript; F.F. participated in conceiving and designing the study, managed exercise testing, contributed to preparation of the manuscript. All authors read and approved the final version of the manuscript.

\section{Funding}

No external funding has been received for this study.

\section{Declarations}

\section{Ethics approval and consent to participate}

The protocol of the present study was a part of the clinical procedures for the functional evaluation of exercise performance which are in allowance with the institutional ethical standards of Università degli Studi di Milano for veterinary practices. All horses' owners gave a written informed consent to participate.

\section{Consent for publication}

Not Applicable.

\section{Competing interests}

None of the authors declares a conflict of interest that could be perceived as prejudicing the impartiality of the reported information.

\section{Author details}

${ }^{1}$ Present Address: Croce Rossa Italiana, Comitato Nazionale, Via Ramazzini 37, Roma, Italy. 'Laboratorio di Medicina Sportiva del Cavallo "Franco Tradati", Università degli Studi di Milano, Lodi, Italy. ${ }^{3}$ Istituto di Fisiologia Clinica, CNR, Sede di Milano, Milano, Italy.

Received: 20 July 2020 Accepted: 25 February 2021

Published online: 16 March 2021

\section{References}

1. Areta JL, Hopkins WG. Skeletal muscle glycogen content at rest and during endurance exercise in humans: a meta-analysis. Sports Med. 2018;48:2091102. https://doi.org/10.1007/s40279-018-0941-1.

2. Constantinopol M, Jones JH, Weibel ER, Taylor CR, Lindholm A, Karas RH. Oxygen transport during exercise in large mammals II. Oxygen uptake by the pulmonary gas exchanger. J Appl Physiol. 1989;67:871-8. https://doi. org/10.1152/jappl.1989.67.2.871.

3. Crook TC, Wilson A, Hodson-Tole E. The effect of treadmill speed and gradient on equine hindlimb muscle activity. Equine Vet J Suppl. 2010;38: 412-6. https://doi.org/10.1111/j.2042-3306.2010.00222.x

4. Evans DL, Rose RJ. Cardiovascular and respiratory responses in thoroughbred horses during treadmill exercise. J Exp Biol. 1988;134:397-408.

5. Gehr P, Erni H. Morphometric estimation of pulmonary diffusion capacity in two horse lungs. Respir Physiol. 1980;41:199-210. https://doi.org/10.1016/ 0034-5687(80)90052-3.

6. Genovese RL, Rantanen NW, Hauser ML, Simpson BS. Diagnostic ultrasonography of equine limbs. Vet Clin North Am Equine Pract. 1986;2: 145-226. https://doi.org/10.1016/s0749-0739(17)30738-1.

7. Greene J, Louis J, Korostynska O, Mason A. State-of-the-art methods for skeletal muscle glycogen analysis in athletes-the need for novel non-invasive techniques. Biosensors (Basel). 2017;7(1):11. https:/doi.org/10.3390/bios7010011.

8. Helge JW, Richter EA, Kiens B. Interaction of training and diet on metabolism and endurance during exercise in man. J Physiol. 1996;492:293306. https://doi.org/10.1113/jphysiol.1996.sp021309.

9. Hill JC, Millán IS. Validation of musculoskeletal ultrasound to assess and quantify muscle glycogen content. A novel approach. Phys Sportsmed. 2014:42:45-52. https://doi.org/10.3810/psm.2014.09.2075.

10. Hodgson DR, McKeever KH, McGowan CM. The athletic horse: principles and practice of equine sports medicine: second edition. Elsevier. 2014 https://doi.org/10.1016/C2009-0-46058-6.

11. Jones JH, Longworth KE, Lindholm A, Conley KE, Karas RH, Kayar SR, Taylor CR. Oxygen transport during exercise in large mammals I Adaptive variation in oxygen demand. J Appl Physiol. 1989;67:862-70. https://doi.org/10.1152/ jappl.1989.67.2.862.

12. Kawai M, Minami $Y$, Sayama $Y$, Kuwano A, Hiraga A, Miyata $H$. Muscle fiber population and biochemical properties of whole body muscles in thoroughbred horses. Anat Rec (Hoboken). 2009;292:1663-9. https://doi.org/10.1002/ar.20961.

13. Kayar SR, Hoppeler H, Lindstedt SL, Claassen H, Jones JH, Essen-Gustavsson $B$, Taylor CR. Total muscle mitochondrial volume in relation to aerobic capacity of horses and steers. Pflugers Arch. 1989:413:343-7. https://doi. org/10.1007/BF00584481

14. Lacombe VA, Hinchcliff KW, Taylor LE. Interactions of substrate availability, exercise performance, and nutrition with muscle glycogen metabolism in horses. J Am Vet Med Assoc. 2003;223:1576-85. https://doi.org/10.2460/ja vma.2003.223.1576. 
15. Lacombe VA, Hinchcliff KW, Geor RJ, Baskin CR. Muscle glycogen depletion and subsequent replenishment affect anaerobic capacity of horses. J Appl Physiol. 2001;91:1782-90. https://doi.org/10.1152/jappl.2001.91.4.1782.

16. Lindholm A, Bjerneld H, Saltin B. Glycogen depletion pattern in muscle Fibres of trotting horses. Acta Physiol Scand. 1974;90:475-84. https://doi. org/10.1111/j.1748-1716.1974.tb05610.x.

17. Lindner A, Dag S, Marti-Korff S, Quiroz-Rothe E, López Rivero JL, Drommer $W$. Effects of repeated biopsying on muscle tissue in horses. Equine Vet $J$. 2002;34:619-24. https://doi.org/10.2746/042516402776180188.

18. Nieman DC, Shanely RA, Zwetsloot KA, Meaney MP, Farris GE. Ultrasonic assessment of exercise-induced change in skeletal muscle glycogen content. BMC Sports Sci Med Rehabil. 2015;7:9. https://doi.org/10.1186/s131 02-015-0003-z eCollection 2015

19. Olsson KE, Saltin B. Variation in total body water with muscle glycogen changes in man. Acta Physiol Scand. 1970;80:11-8. https://doi.org/10.1111/ j.1748-1716.1970.tb04764.x.

20. Ringmark S, Revold T, Jansson A. Effects of training distance on feed intake, growth, body condition and muscle glycogen content in young Standardbred horses fed a forage-only diet. Animal. 2017:11:1718-26. https://doi.org/10.1017/S1751731117000593.

21. Snow DH, Harris RC. Effects of daily exercise on muscle glycogen in the thoroughbred racehorse. In: Persson SGB, Lindholm A, Jeffcott LB, editors. Equine exercise physiology 3. Davis: ICEEP Publications; 1991. p. 299-304. http://www.iceep.org/pdf/iceep3/_1130110421_001.pdf.

22. Snow DH, Baxter P, Rose RJ. Muscle fibre composition and glycogen depletion in horses competing in an endurance ride. Vet Rec. 1981;108:3748. https://doi.org/10.1136/vr.108.17.374.

23. Snow DH, Harris RC, Gash SP. Metabolic response of equine muscle to intermittent maximal exercise. J Appl Physiol. 1985;58:1689-97. https://doi. org/10.1152/jappl.1985.58.5.1689.

24. Waller AP, Lindinger MI. Nutritional aspects of post exercise skeletal muscle glycogen synthesis in horses: a comparative review. Equine Vet J. 2010;42: 274-81. https://doi.org/10.2746/042516409X479603.

\section{Publisher's Note}

Springer Nature remains neutral with regard to jurisdictional claims in published maps and institutional affiliations.

Ready to submit your research? Choose BMC and benefit from:

- fast, convenient online submission

- thorough peer review by experienced researchers in your field

- rapid publication on acceptance

- support for research data, including large and complex data types

- gold Open Access which fosters wider collaboration and increased citations

- maximum visibility for your research: over $100 \mathrm{M}$ website views per year

At $\mathrm{BMC}$, research is always in progress.

Learn more biomedcentral.com/submissions 